\title{
Tablet for Two: How do Children Collaborate around Single Player Tablet Games?
}

\author{
Rowanne Fleck, University of Birmingham \\ Asimina Vasalou and Konstantina Stasinou UCL Knowledge Lab
}

\begin{abstract}
Tablet computers are increasingly used in school classrooms. However, despite the fact that these devices are conceived as single-user devices, and most games or apps developed for them are designed for single-users, pairs or groups of students usually use these devices. Surprisingly little research has been done to explore the ways in which these devices support or not children's collaboration - instead research has focused on larger tabletop computers, or on collaboration around configurations of multiple tablet computers. In this paper we present a case-study analysis of pairs of children playing single player tablet games together. We use a combination of temporal video analysis and the Collaborative Learning Mechanisms (CLM) framework previously developed to understand collaboration around surfaces. This analysis aims to unpack collaborative interactions around these devices and identify ways in which successful and less successful collaborations occur. A comparison of our findings to previous studies of interactions around larger tabletop surfaces reveals some of the ways interactions around tablets differ to these. We use these understandings to begin to outline some of the issues to take into consideration when facilitating and designing for children's collaboration around single tablet computers.
\end{abstract}

\section{Introduction}

Collaboration plays an important role in children's learning. Through collaborative processes, children explain and question their understanding of learning tasks, which acts as a trigger to their learning (Lai, 2011). Collaborative processes have been viewed both as a means to cognitive learning, and as a way for children to develop their social and emotional skills. It is thus not surprising that researchers working in the area of digital technology and learning have explored the ways in which collaboration can be engendered through the technology. Tabletop surfaces, in particular, have been a focus of much of this past work owing to their opportunity for multi-touch interactions and physical resources shared by different children (Falcão and Price, 2009). In addition to contributing new insights on how to design collaborative tasks that capitalize on multi-touch affordances (e.g. Falcão and Price, 2009; Fleck et al., 2009), or developing new analytic tools for studying collaboration (e.g. Fleck et al., 2009), this previous research has looked at the way that such technologies support the process of collaboration.

Despite a rich body of research evidencing the opportunities of multi-touch tabletop technology in orchestrating collaborative situations, technology use in the classroom has been increasingly reliant on small surfaces - namely tablets. Given the collaborative potential these devices are touted to offer, and the limited financial resources available at schools, research has shown that teachers will often request children work in pairs using tablet-based apps teaching curriculum specific skills (Fallon and Khoo, 2014). However, these apps are frequently designed without collaboration as an explicit objective (Benton et al., 2018; Falcão and Price, 2009). Furthermore, evidence suggests that classroom interactions around tablet computers are frequently only loosely orchestrated and teachers can be unclear on how to support children's collaboration around them in practice (Davidsen, 2016). This can lead to potentially uncollaborative situations where asymmetry of action exists, with the learning potential of the tablets remaining un-realised (Dillenbourg, 1999). Thus our research is motivated by classroom practice, and aims to understand if and how collaborative learning can occur around single player tablet games for literacy. This understanding has the potential to inform best practice around the use of single player tablet games in the classroom, and also the design of new games-based learning tasks that facilitate collaboration around such surfaces.

In order to do this, we take the approach of seeking to understand the process of collaboration that unfolds around these games by studying the temporal interactions between pairs of children aged 9-11 through three case studies. The pairs were familiar with each other, and two of them shared a friendship. Our findings show that children's collaboration is highly dependent on their joint collaborative orientation, i.e., their reciprocal positive attitude to work together on a task and motivation in seeing another child succeed in the task. When children's orientation is collaborative, it leads to highly intertwined forms of coordination where the single resource, 'tablet', becomes malleable to both children's action and influence. We also find that the game mechanic plays a key role in whether coordination is followed by elaborative, symmetrical collaborative conversation. Conversely, when children approach game play as a solitary activity governed by sequential rules of turn-taking, joint attention is not achieved, leaving one of the children excluded from the activity. Building on our findings, we offer implications for designing or facilitating productive collaboration around tablets. We also highlight implications for designing tasks that support the duality of individual and collaborative modes of learning, and discuss how our findings compare to previous work looking at collaborative learning around tabletop surfaces.

\section{Relevant Work}




\section{Definitions and Concepts of Collaboration}

Previous research has found a relationship between collaboration and learning in a range of digital technology configurations such as traditional setups, tangible or tabletop tasks, and so on. Whilst some of this work presents improved learning outcomes as evidence that a particular technology has supported effective collaboration (e.g. Do-Lenh et al., 2009; Piper and Hollan, 2009), other research focuses more on the process of collaboration, seeking to understand the precise mechanisms of collaboration around these technologies, and the role they play in learning (Fleck et al., 2009; Rick et al., 2009; Davidsen, 2016). This latter body of research, and the perspective we explore in this paper, has been motivated by the view that a deeper understanding of how collaboration works, and how it can be effective, can inform both design and human interventions that strengthen the quality of children's learning.

Before we begin to ask how collaboration in learning is achieved, however, it is necessary to define it. Taking a view that emphasizes togetherness and joint activity, Dillenbourg (1999) defines collaborative learning as "a situation in which two or more people learn, or attempt to learn something together". A number of approaches have been used to explore how children collaborate during educational activities around technology, and in particular peer 'exploratory' talk is often studied as a window into this (Kucirkova et al., 2014) Exploratory talk involves children's justifications of their reasoning and suggestions for alternatives, and has been associated with positive learning outcomes (Mercer, 1994; Mercer and Wegerif, 1998).

Similar to Dillenbourg, Lai (2011) talks about collaboration as "a mutual engagement of participants in a coordinated effort to solve a problem together”. Lai's definition appreciates the additional importance of coordination, i.e., the assurance that all collaborators are working on the same task. This view emphasises that the process of collaboration involves both discussion and activity around the learning task, as well as work to monitor and coordinate the on-going learning activity (Fleck et al., 2009). Therefore, past empirical research has not only considered children's talk, but has shown that collaboration is accomplished through both verbal and non-verbal behaviours (e.g. gesture, touch) reflecting an embodied view of interaction and learning (Fleck et al., 2009; Davidsen, 2016).

\section{Surfaces and Collaborative Learning}

The opportunities that surfaces offer to children's collaborative learning have been explored extensively in previous research albeit predominantly in tabletops (e.g. Hornecker at al., 2008; Rick et al, 2009; Falcão and Price, 2009; Fleck et al., 2009; Ioannou et al., 2013). Exploring how touch shapes collaborative learning on the tabletop, one study examined how children aged 7-10 interact (verbally and non-verbally) around a single-touch and multi-touch tabletop surface (Harris et al., 2009). The findings showed that there was more task-based talk when children had simultaneous control of the surface (multi-touch condition). In comparison, when only one child could interact with the surface at a given moment (singletouch condition) there was more talk about turn-taking, with children showing stronger mutual awareness than in the multi-touch condition. They also found that the verbal participation of students was equal in both multi and single touch conditions, although physical participation was much higher in the multi-touch condition given the possibility for simultaneous action (Rick et al., 2009). Therefore, through distributing control over the task, multi-touch may have facilitated more learning related to the task, whereas the restrictions on control in the single touch situation led to children practicing turn-taking, i.e. general collaborative skills. While this work suggests that both the surface itself and the task design can impact on children's emergent social interaction, Ioannou et al (2003) show that group dynamics play an equally important role, with some children often dominating the interaction with the tabletop and the solution to the task.

In contrast to tabletops, there is less research that specifically focuses on tablet surfaces. One exception is work by Falloon (2015) who held focus groups with primary school children aged 8-11 about their perceptions of tablets in collaborative learning exploring the role of tablet affordances in collaborative action. Children valued the tablet's portability as it fostered more movement, and found it easy to share media through display visibility. Nonetheless, while tablets technically allowed for multi-touch interactions, perhaps due to the size of the screen, the children preferred turntaking rather than crowding and confusing the ground rules of the interaction.

In another study, Falloon and Khoo (2014) looked at the process of collaboration around tablets, focusing on the quality of 5-6 year old primary school children's talk while using tablets in pairs. The authors compared their findings with past empirical work arguing that children's talk around closed tasks (e.g. quizzes) was less 'thoughtful' than what they observed in the open-ended tasks of their study. What is also notable in this research is that children were collaborative in the sense that 'there were few disputes and disagreements', yet despite engaging in on-task conversations, the quality of these was not predominantly critical. Conversely, empirical research on multi-touch tabletop surfaces has challenged the view that 'disputes' are negative to collaboration. What may look like unproductive collaboration for on-task learning can be beneficial for re-establishing collaboration. For example, children's actions can intrude on, or block the actions of others as they work around multi-touch, or tangible surfaces. While disrupting and taking time away from the learning task flow, these actions can also foster children's mutual awareness about the task and bring everyone back to the same goal (Falcão and Price, 2009; Fleck et al., 2009). Therefore, as Davidsen (2016) explain, the role that different behaviours may play in collaboration must be interpreted 'in context'.

\section{Research Motivation and Questions}


To summarise, although tablet-based apps are often designed for individual use, their use by pairs or groups of children is ubiquitous in everyday classrooms. A number of researchers have previously argued that the hype around tablet use in the classroom has not been met with adequate empirical research that unpacks the role of the tablet in children's collaborative learning (Falcão and Price, 2009; Clark and Luckin, 2013; Haßler et al., 2015). Therefore, it has not yet been established if the shared use of apps on a tablet, whose design does not specifically promote symmetrical actions between children, constitutes a collaborative situation that engenders interactions triggering learning, and more so, how this happens. Classroom research, in particular, has shown that primary school children's interactions around tablets are loosely orchestrated by teachers, suggesting a potential knowledge gap in how to construct these kinds of situations (e.g. Davidsen, 2016; Halloluwa et al., 2018). Therefore, research in this area could contribute a new theoretical understanding of collaboration under a prevalent classroom scenario, as well as provide teachers with much needed digestible and actionable advice on how to construct a collaborative situation with tablets in the classroom (Dimitriadis et al., 2013). The present research seeks to address this gap through exploratory case study research.

Collaboration is a complex socially constructed process, taking place over time. As the aforementioned studies show (e.g. Falcão and Price, 2009; Ioannou et al., 2013; Falloon, 2015) collaborative learning is shaped by the design of the hardware, the software, the nature of the learning task, as well as the learners' ways of engaging with the task and with each other (also see Mercer, 1994). Moreover, it is not limited to talk, but is performed in multimodal ways in service of two mechanisms: collaborative discussion and coordination (Fleck et al., 2009). This conceptualisation of collaborative learning highlights a methodological challenge, i.e., the need to understand the social complexity and temporality of collaborative processes. In applying a situated, multiple case study approach that considers three pairs of children playing a tablet game we aim to unpick the complexity of context. Given the dearth of research in this area, our exploratory approach informs the following research questions:

- Does collaboration occur when children play single-player tablet games? Under what conditions does collaboration occur?

- What characterizes this collaboration, how does it evolve, and when is it productive?

\section{Methodology}

\section{Research Approach}

We take a multiple case study approach to build a rich account of how the process of collaboration unfolds and is achieved by three pairs of children when playing a tablet game. The game was designed for single player interaction and supported single touch. Case studies typically focus on smaller units that are bounded by the phenomenon of interest. In our study, the case is the child pair jointly using the tablet. Case study research is appropriate when the researcher seeks to understand a phenomenon in its context without intervening on the events (Flyvbjerg, 2006; Yin, 2018). In foregrounding the role of context, it is possible to investigate subtle and temporal interactions between multiple variables of interest. In our research this was deemed important to understand the dynamics of collaboration and to identify the possible differences between each pair of children. To accomplish this, we conducted a micro level video analysis of the three child pairs' interactions during their game play.

One of the often-cited criticisms of case study research is their lack of statistical generalisation. As both Yin (2018) and Flyvbjerg (2006) explain, case studies may not yield generalisations to populations but support 'analytic generalization' by contributing new and testing existing theoretical propositions (also Stebbins, 2001). In the case of our research, we seek to generate theoretical insights about collaboration and digital surfaces that confirm and expand existing theory in the area of collaborative learning and social interaction around surfaces.

\section{Participants and Context}

The research reported in this paper was part of a broader research project exploring the remedial value of learning games for struggling readers aged 9-11. Twenty children participated in the research who were identified by their school as struggling readers. The children were recruited by one of the authors and all attended a primary school located in London, UK. Besides their need for additional practice in the domain of reading, the children had no other reported difficulties. Four children were removed at a time from class to play a tablet game called Word Matter in 30-minute weekly sessions for a total of 10 weeks, excluding a one-week school holiday.

At the start of the study, the children were provided with an instructional session to ensure their understanding of the game's learning goals and the game mechanics. The children went on to use the tablet individually except for the final session where it was possible to investigate the collaborative potential of single player tablet situations. In this final session, all of the children used the games in pairs with each pair playing the game between 15-20 minutes. Only three of these pairs had given consent to participate in video observations and form part of the present study. Therefore, six primary school children participated in total in this part of the research comprising four boys and two girls. Two of the pairs were friends (Daniel and Arthur; Nina and Penny) and the third pair (Kyle and Sam) had gained a familiarity over the nine previous weeks to the study. This final session was facilitated by a researcher who had previously participated in the design of the games and was also observed by one of the authors of this paper. Children were asked to work together on the tablet, which was placed between the children flat on the table surface. Children self-organised in pairs based on 
their existing seating arrangement, meaning that children who had chosen to sit closer together played together. Figure 1 demonstrates the technology set up (to maintain children's anonymity a line figure is used to reproduce a video still).
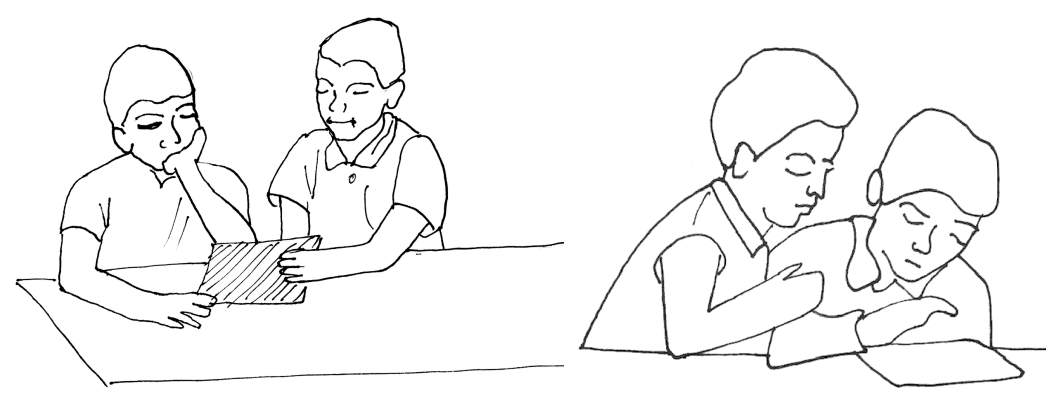

Figure 1- Two pairs of children playing the tablet-based game. Left (case study 1): Daniel and Arthur have joint physical access to the tablet; Right (case study 2): Sam uses his body to restrict access to Kyle's view of the tablet.

Mirroring reports of classroom practice with tablets (e.g. Davidsen, 2016; Halloluwa et al., 2018), if the facilitator detected that there was territorial behaviour over the tablet by one of the children, the children were prompted to negotiate its use.

The research followed the ethical guidelines of the British Educational Research Association and was granted ethical approval by our University ethics committee. All of the children and their parents provided informed consent prior to their participation. Parents gave written consent for their children prior to the study. In contrast, the consent process with the children was managed by the researcher on the first day of the study. Children were provided with an information sheet and consent forms written in child friendly language. As the children engaged with the written materials, the researcher verbally discussed its contents with them to ensure they understood the nature of their participation. In respecting children's anonymity, we use pseudonyms when reporting children's quotes.

\section{Game}

The game, Word Matter, was designed to teach children reading skills found in the primary school curriculum. It was delivered through a set of nine mini game activities. Each game activity had a discrete learning aim that the child was presented with at the onset. As children's mastery was built up, the child unlocked new game characters that represented their progression and also unlocked new games. Therefore, in playing the game, the children had a degree of autonomy to choose a game mechanic and reading skill they wanted to practice from those they had unlocked.

Within the current dataset, three mechanics were encountered by the child pairs (see Figure 2):

- 'Junk Yard': this game required the player to segment words in syllables or morphemes and then to stack the word parts (which transform into junk) into rows, similar to a Tetris timed mechanic. The child could engage in correct segmentation, but lose in the game if the stacks were not arranged quickly.

- $\quad$ 'Field': this was a non-timed game where the children must identify which linguistic rules apply to a stream of suffixed words that appear one by one. The learning aim of this game was to develop children's metalinguistic knowledge.

- $\quad$ 'Mail Delivery': the player had a parcel to deliver while trying to avoid monkeys who want to steal the parcels. Once at the customer's door, the player needed to tap as many times as the syllables of a word presented earning bananas as rewards for the correct answer.
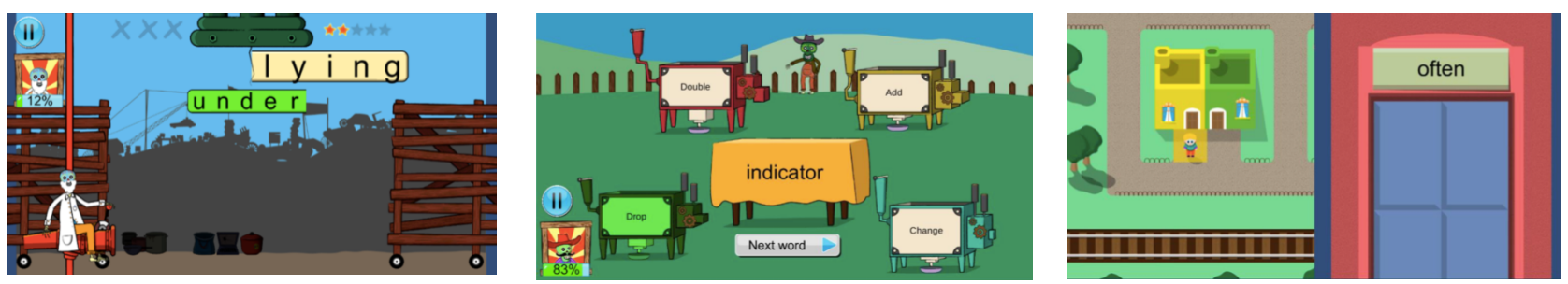

Figure 2 - Games from left to right: Junk Yard, the Field, Mail Delivery

\section{Video Analysis}

As we described above, the data used in this study is from the final week of game play. During this week children played the game on the tablet in pairs, with three pairs in total granting consent to participate. Each child pair was video 
recorded for later video analysis (Derry et al., 2010). The camera was placed discretely on top of a book case with a front view of the children playing the games. The recording took place during the entire game play session. To contribute to a better contextual understanding, we temporally aligned the video recordings with game logs that indicated which game and what content each child pair was viewing.

Instead of selecting specific 'critical' interaction events, given our goal to understand the temporal unfolding of children's interaction, we engaged in a micro level video analysis of the entire session. While Yin (2018) proposes the use of time-series analysis in case studies to test specific propositions that take place over time, our aim was to produce a descriptive temporal account of children's patterns of collaboration, lack of, or breakdown. Reflecting our multimodal focus on collaboration, we paid attention to the verbal behaviours of the children (e.g. when they voiced out game content) and their non-verbal behaviours (e.g. when they used their hands to tilt the tablet) documenting how they shape the next sequence of events. For example, while one child was playing the game, another physically intervened to influence game play, resulting in the first child moving the tablet closer to her body. Additionally, reflecting our interest in exploring how technology mediates collaboration, we documented the role of game and tablet in shaping interaction. For instance, the portability of tablets both supported coordination when used as a shared space on the table, and impeded on coordination as children at times kept the tablets close to their body. Whilst past work with tabletops has sometimes focused on the spatial dimension of interaction given the size of the surface (e.g. Brudy et al., 2018), spatial interactions around tablets are fine grained and thus require a micro-analytic approach to identify them. The video analysis we conducted allowed us to capture children's relational micro behaviours, such as pointing or tilting, as they applied to the tablet surface and game task.

\section{The Collaborative Learning Mechanism (CLM) Framework}

Having produced an initial moment-to-moment descriptive account of the unfolding of children's interactions, in a subsequent step of our analysis, we focused on identifying the collaborative patterns present within each case. This was achieved through the Collaborative Learning Mechanism (CLM) framework (Fleck et al., 2009). The CLM framework, based on a review of the psychological and learning literature on collaboration, outlines mechanisms considered important for collaborative learning. Through empirical examination of children's collaborative tasks on multi-touch tabletop surfaces, the authors presented an extended CLM tabletop version of the framework. This CLM tabletop framework identifies both verbal and physical examples of mechanisms of collaborative discussion and mechanisms of coordinating collaboration observed when children collaborated around a multi-touch tabletop (see Table 1). The choice to use the CLM was made because of its grounding in a review of theories of collaborative learning, its contextualisation of these theories to digital surfaces, and its recognition of multimodal collaborative behaviours. Thus, while the CLM framework aligns with our theoretical view on collaboration, it also recognises the specificity of surface technologies. We briefly introduce the CLM tabletop mechanisms that support the two facets of collaboration, i.e., 'collaborative discussion and action' and 'coordinating collaborative discussion and action', and the new additions we made to the framework in adapting it to create a CLM tablet version of the framework.

\section{Collaborative Discussion and Action}

The mechanisms of collaborative discussion described in Fleck et al. (2009) included ways in which children both verbally and physically made and accepted (task-based) suggestions, as they worked together around the tabletop. For example, not only did children verbally suggest ideas about how they might solve the task to their peers, they also physically gestured to explain, or demonstrated their suggestions by moving icons on the tabletop. Similarly, they did not just listen to each other's suggestions and agree with them, they also watched what others did, and physically enacted other's suggestions by way of agreement. However, in their research they found that children did not always immediately agree with each other, and collaborative discussion often included negotiation and even disagreement, as Mercer and Wegerif (1998) have also reported. While this negotiation involved strategic actions, e.g. watching and responding to each other's suggestions, children also engaged in explicit disagreements, e.g. blocking others' interaction either physically by: shielding areas of the tablet; touching icons on the surface meaning no-one else could move them (touch-blocking); or by knocking other children's arms out the way. However, it was observed that these explicit disagreements often led to children explaining and justifying their ideas in order to break the impasse, and thus, in some cases, were part of successful collaborative discussion.

\section{Coordinating Collaborative Discussion and Action}

The mechanisms of coordinating collaboration are described in CLM as those that ensured children were able to maintain joint awareness of what each other were doing and thinking when interacting with the tabletop surface task. In addition to the mechanisms of collaborative learning introduced above, which necessarily require joint awareness and attention, coordination mechanisms included verbal coordination behaviours such as narrations i.e. children voicing out what they are doing in order to enable the monitoring of each other's activities. They also involved physical coordination behaviours such as intrusions - whereby one child's physical interaction on the tabletop accidentally intruded into what another child was doing, bringing their attention together. 


\begin{tabular}{l|l}
\hline Mechanisms of Collaborative Discussion and Action & Code \\
\hline Making Suggestions & MS-V \\
\hline Verbally suggesting ideas, giving opinions & MS-P \\
\hline Physically (e.g. gesturing, demonstrating own ideas or opinions) & \\
\hline Accepting Suggestions & AS-LW \\
\hline Listening to and watching others & AS-D \\
\hline Demonstrating other's ideas & AS-A \\
\hline Asking for opinions or ideas & AS-C \\
\hline Asking for clarifications of other's suggestions & \\
\hline Negotiation & N-MA \\
\hline $\begin{array}{l}\text { Making, watching and responding to each other's suggestions, } \\
\text { opinions, questions (as above) }\end{array}$ & N-AS \\
\hline Making and demonstrating alternative suggestions & N-D \\
\hline $\begin{array}{l}\text { Disagreeing - explaining/justifying own ideas, verbal blocking, } \\
\text { physical blocking (shielding, touch-blocking, knocking others' hands away), } \\
\text { undoing. }\end{array}$ & \\
\hline Mechanisms for Coordinating Collaborative Discussion and Action & \\
\hline Maintaining joint awareness and attention & \\
\hline $\begin{array}{l}\text { Narrations } \\
\text { Intrusions * }\end{array}$ & JAA-N \\
\hline $\begin{array}{l}\text { Regulation of access ** - ensuring own/others visual (and physical) access } \\
\text { to the screen. }\end{array}$ & JAA-I \\
\hline Turn-taking** & TAA \\
\hline Taking turns to physically interact; verbally discussing turns & \\
\hline
\end{tabular}

Table 1 CLM Tablet Framework, extended from the CLM Tabletop Framework (Fleck et al. (2009): Items with * are from the CLM Tabletop framework but were not observed around tablets in our research. Items with ${ }^{* *}$ were observed around tablets and are additions we have made to the mechanisms reported in Fleck et al. (2009).

The CLM tabletop framework describes the mechanisms and the manifestation of behaviours which are associated with 'effective collaborative learning' around tabletops. In our research, the CLM tabletop framework was used in a top down analysis of the three cases to identify collaborative mechanisms around the tablets in relation to those previously described around multi-touch tabletops. In addition, the initial bottom up analysis carried out revealed additional mechanisms and behaviours used by children in their collaborative learning around tablets, i.e. regulation of access to the tablet and turn-taking, and was used to generate an initial instantiation of a CLM tablet framework (see Table 1). Regulation of access was considered an additional mechanism for maintaining joint awareness and attention, and included any discussion or action the children engaged in in order to ensure either themselves or their partner had visual (and physical) access to the tablet. Turn-taking was considered as an additional mechanism for coordinating collaborative discussion and action, and included taking turns or sharing of physical interaction with the tablet, and any discussion related to negotiating this.

The next section presents the three case studies in detail. In each case we describe the temporal interactions between children with collaboration mechanisms from the CLM tablet framework appearing in brackets. Each case is followed by a brief interpretive analysis that identifies the different factors that contributed, or impeded, in achieving effective collaboration.

\section{Findings}

\section{Case study 1}

\section{Descriptive temporal analysis}

The two children, Daniel and Arthur, do not make explicit rules about their coordination. Both initially have a physical role in the activity [TT]. Arthur holds the tablet with one hand ensuring both he and Daniel have visual and physical access to the screen [JAA-RA] and Daniel uses his hand to make game choices [MS-P]. The children play the 'Junk Yard' game. Daniel takes the lead in choosing the correct word splits. He verbalises what he is doing aloud [JAA-N], e.g. words chosen, game strategies employed, game performance, as Arthur watches [AS-LW]. At times, there is a performative element in how Daniel engages in these narrations with the tone of his voice changing when he is successful, or when he fails to progress. Arthur watches Daniel's actions on the tablet primarily taking the role of the listener [AS-LW]. There are only a few moments when Arthur engages in narration himself. On those occasions he mirrors Daniel by vocalising a 
word split 'un/happy' and a game strategy 'quick!' [JAA-N]. Therefore, the stream of narrations appears to come from Daniel who is controlling the game. Daniel vocalises the correct response and at times Arthur interprets this as a suggestion, in turn making the game choice [AS-D]. In addition to this, Arthur claims his own expertise and subtly interjects by tapping on the screen [MS-P]. Each time Daniel chooses the correct word response [MS-P], Arthur watches and listens to Daniel's suggestion [AS-LW] and uses his finger to successfully stack the junk in a row [MS-P] [N-MA; TT]

Half way through the session, the children ask the tutor for support having lost their place in the game. With the tutor's help, they choose a new game, the 'Field' (see Fig 1). In this game the children must identify which linguistic rules apply to a stream of suffixed words that appear one by one. Unlike the 'Junk Yard' game, this game is not timed. It is here that the consistent pattern of dynamics observed in the previous game play between the two children shift as they encounter new words.

In the 'Field' game, both Daniel and Arthur have individual turns [TT], where they independently choose a game response (a linguistic rule). Turn-taking does not inhibit the social interaction. Instead, children's interactions are interlocked. At each turn, one child has a go at vocalising the target word [MS-V] (sometimes both children vocalise together) while the other child chooses the response [AS-D]. Moreover, at times the children support each other's understanding. When Daniel misses the suffix as he vocalises a target word [JAA-N], Arthur repeats the word in its correct form [MS-V]. In a similar interaction, when a new word 'getting' appears, Daniel announces the 'doubling' rule that applies to it [MS-V]. Prompted by Arthur's question 'is it'? Daniel goes on to explain the rule to Arthur [AS-C]. As the session unfolds, Daniel starts to verbalise each target word and in turn asking, or directing his gaze on [MS-V], Arthur for his thoughts, who accepts these suggestions [AS-A] while occasionally interjecting with his own [N-MA]. This questioning gives a voice to both children to make equal suggestions. Throughout this second game play there are only two occasions in which Daniel has the opportunity to support Arthur but doesn't.

\section{Reflections from case 1}

It is clear that the two children perceive their interactions with the game as a joint, or collaborative, activity: i.e. they work together towards a shared goal to successfully complete the game. Evidence of this is verbally expressed when Daniel vocalises the outcome of their mutual performance 'we only got one wrong!', or in another moment when the two children synchronise a narration of the correct response 'po-si-tion'. In placing the tablet between them on the table they maintain joint access to the tablet at all times. Although they do take turns to physically control the game, both children attend to and are engaged in the task - i.e. maintain joint attention - in short iterative turns. Therefore, the placing of the tablet and the nature of touch-screen interaction makes it possible for the children to seamlessly switch who makes physical actions in the game.

This case shows the impact of the game task on collaborative conversation. During the second 'Field' game, both the children make, accept and ask for suggestions about the learning content of the game, and there is evidence of negotiation where they disagree, explain and learn from each other. Additionally, joint attention is performed and maintained by both children. In contrast, during the first 'Junk Yard' game, although they both maintain joint awareness through positioning the tablet in a way that ensures they both always have visual and physical access to the screen, Daniel facilitates the pair's joint awareness on the game's learning aims through his narrations, and there are missed opportunities for Daniel to explain his thinking, or to encourage meaningful contributions from Arthur. Whilst both children make suggestions, Daniel's are about the learning content, whereas Arthur's are only about the game mechanics. Therefore, the way in which the pair divides the game play does not support them both making an intellectual learning contribution to the game.

\section{Case 2}

\section{Descriptive temporal analysis}

Sam and Kyle set the tablet on the table. Spatially the tablet sits between them, so that both can see it and have equal access to it [JAA-RA]. They decide to take turns with each child having a single turn with the game [TT]. Sam declares his preferred game 'I want to go to the junk thing (Junk Yard) Kyle!' [MS-V]. Kyle starts to play first. Sam appears to be distracted. His attention is not focused on the tablet, or what Kyle is doing. He speaks with the other two children who are in the room playing on another tablet, missing that Kyle has played at least once. Sam asks Kyle 'what did you do?' and Kyle alerts Sam that he has already had a turn [TT]. However, Sam's attention is quickly diverted back to other things going on in the room. He checks back with Kyle asking if he is 'nearly there' [TT] establishing his right to have a turn. Observing Sam's directed attention on the game, Kyle vocalises narrations of what is happening in the game [JAA-N]. His turn ends with Sam claiming his turn 'now, I go!' [TT]. Kyle chooses a game for Sam and hands over the tablet [MS-P]; [TT], to which Sam protests and selects his preferred game 'Junk Yard' [N-D].

Similar to Sam's response in his role as an observer, Kyle initiates and engages in conversation with the two other children in the room, only momentarily gazing at the tablet screen to see what Sam is doing. It is only on one occasion when the interaction between the children becomes interrelated. While Sam is playing, he is perceived by Kyle to struggle with stacking the junk in one of the games. Kyle steps in claiming some expertise 'I know how to get them in a row' [NAS]. Sam puts his head on the table watching Kyle interacting with his game from the side [AS-LW], but eventually reclaims his turn by placing his fingers on the screen and resuming the sole control [N-D, TT]. After this, Kyle becomes disruptive to Sam's game play. Twice he draws Sam into a tangential conversation with the other children in the room. 
Later he hugs Sam who resists bringing his own attention resources back to the game: 'Stop! Am I on the right game?'. Toward the end of Sam's game play, Kyle begins to disrupt his game choices by intentionally choosing the wrong response. This results in Sam failing in the game and changing his spatial arrangement of the tablet by placing the device in between his arms to protect it until his turn is over.

\section{Reflections from case 2}

In contrast to case 1, this pair mostly employs an individual orientation to the game and there is no evidence that the children are working together towards a shared goal. Rather they perceive themselves as having to 'wait' to take their turn whilst the other child is playing. Whilst it is possible to see evidence of some of the behaviours described in the CLM tabletop framework, it is also clear that these are rarely evidence of the collaborative mechanisms working well or leading to effective collaboration. For example, turn-taking behaviours do not coordinate collaboration, but rather coordinate a sequence of individual work. There are examples of physical blocking and disagreement, which do not then lead to negotiation, but rather a breakdown in conversation and joint attention on the task. Similarly, to case 1, the two children initially regulate access to the tablet by placing it between them so they can both see/have access to the screen. However, this spatial arrangement does not lead to coordinating conversation or action, and there is very little joint attention. As each of the children plays the game, the other is distracted. Most of the utterances supporting coordinating collaboration serve the purposes of supporting individual turn-taking. Kyle maintains joint attention and collaborative conversation at one point when Sam is physically in control of the game. However, this seemingly productive event also leads to Kyle reclaiming the tablet from Sam. When Sam takes back control, Kyle becomes disruptive to Sam's game play evidencing his individual orientation. As a result, there is almost no productive coordination or collaborative conversation in evidence during this interaction.

\section{Case 3}

\section{Descriptive temporal analysis}

Penny begins her game play exclaiming 'I have got all the characters!' to indicate her previous success in the game. Unlike the other two pairs of children (case 1 and 2) who were playing with a generic account, it is Penny's game account and tablet that Nina is sharing. Initially Nina mirrors Penny's language by repeating that she too has all the characters in her game account. As Penny vocalises a game choice 'I'm going to go to him. I'm going to go to the train guy' [JAA-N], Nina states the same preference as Penny [MS-V, AS-LW]. Nina's language could foster mutuality and a sense of a joint goal. Yet, Penny does not respond and keeps the tablet close to her upper body while she plays. Finding it effortful to get a view of the screen, Nina bangs her hand on the table, and raises her voice 'Come on! I cannot see! Put it here!' [JAA-RA]. She points to the table and Penny follows suit by lowering the tablet. Quickly both children become momentarily drawn into a conversation with the other two children in the room. While Nina continues to engage in this discussion, Penny turns away from Nina, raises the tablet close to her body and continues her game play. Penny vocalises once what she is doing, namely engaging in game talk [JAA-N], which draws Nina's attention to the screen. Nina occasionally looks at Penny's screen moving her eye gaze away to examine what everyone else is doing, and on occasion gets involved in conversations with the other two children.

Penny controls how the girls play. In the first turn-taking, she hands over the tablet to Nina [TT] having chosen the 'Mail Delivery' game for her (see Figure 1) [MS-P]. Penny goes on to advise Nina how to navigate the game 'follow, the yellow thing' [MS-V]. Nina resists this suggestion raising her voice 'I know! I know!' [N-D]. Unlike the spatial configuration previously chosen by Penny, Nina places the tablet close to the table [JAA-RA], vocalises her game play [JAA-N], and Penny looks attentively to the screen [AS-LW]. Suddenly Nina vocalises that a monkey in the game is coming close [JAA-N] thus risking the loss of the bananas she had so far collected (and those that Penny had previously earned outside the session). Penny quickly interjects 'don't lose my bananas!' and advises Nina to move fast [MS-V]. After a focused moment of game play where both children remain silent, Penny places her hands on the tablet saying 'wait let me fix it' [N-D]. Penny takes complete control and moves the tablet close to her body.

With Penny now in control of Nina's game, the interactions between the two children seem to initially mirror the same pattern as before. When Penny suddenly calls out 'monkey, monkey, monkey!' [JAA-N] to reflect her game state Nina attends to the screen and then asks her peers 'why do the monkeys come after you?' engaging in game talk [AS-A]. After a short conversation about the monkeys eating the banana rewards, Penny's frustration with Nina's previous game play becomes explicit as she replies '(there are no bananas) because you wasted them'. While Nina defends her position, Penny rejects this and reasserts her claim once more [N-D]. Penny so far has expressed dominance over territoriality and game choice. She now extends this dominance into Nina's game performance.

Nina claims her next turn [TT]. The interactions between the children are similar to those before, though in this round Nina performs well in the game. When Penny resumes her turn on the tablet, the dynamics between the two children change. Nina who has so far taken a passive and peripheral interest to Penny's narrations of game play begins to interpret these narrations as points for negotiation challenging Penny's vocalised game choices for the both of them [N-AS]. Instead of only verbally negotiating her views, Nina attempts to influence the game choice by leaning in and clicking on the tablet $[\mathrm{N}-\mathrm{AS}]$ as Penny flings her fingers away [N-D]. These physical negotiations finally result in Penny asking Nina what game she wants to play and setting it up for her in a final game turn [AS-A]. 


\section{Reflections from case 3}

Despite Nina's initial effort to create a collaborative perception of the activity, Nina and Penny seem to approach the game with very different perspectives on their collaboration. As Penny both verbally and spatially defines this as a solitary activity playing on 'her game', through her actions and words, Nina shows a collaborative orientation. Similar to case 2 , the children explicitly coordinate their turn-taking. However, this initial coordination is followed by collaborative conversation only when Nina is playing. Nina performs 'the work' of joint awareness by putting the tablet on the table so they can both see, narrating what she is doing and asking for Penny's suggestions. Penny seems to participate in Nina's collaborative arrangement out of self-interest to maintain her control over the game play. This becomes evident when Penny plays. Discouraging Nina's input into her turn by physically controlling the space, she provides minimal information about what she is doing. This results in Nina's inability to maintain joint attention, and Nina's final physical dominance over Penny's over-regulation of the game play. Whist Nina does attempt to disagree and express her own opinion of events (negotiate) this is not successful until she more assertively physically negotiates at the end of the game, which could be viewed as a positive achievement. However, overall, there is limited evidence that this pair shares the same collaborative goal and the collaborative conversation throughout remains on general game talk related to maintaining/losing rewards, rather than the learning aims of the game.

\begin{tabular}{|c|c|c|c|}
\hline & Case 1 & Case 2 & Case 3 \\
\hline \multicolumn{4}{|l|}{ Mechanisms of Collaborative Discussion and Action } \\
\hline \multicolumn{4}{|l|}{ Making Suggestions } \\
\hline Verbally suggesting ideas, giving opinions & $\bullet$ & $\bullet$ & $\bullet$ \\
\hline $\begin{array}{l}\text { Physically (e.g. gesturing, demonstrating own ideas or } \\
\text { opinions) }\end{array}$ & $\bullet$ & $\bullet$ & $\bullet$ \\
\hline \multicolumn{4}{|l|}{ Accepting Suggestions } \\
\hline Listening to and watching others & $\bullet$ & $\bullet$ & $\bullet$ \\
\hline Demonstrating other's ideas & $\bullet$ & & \\
\hline Asking for opinions or ideas & $\bullet$ & & $\bullet$ \\
\hline Asking for clarifications of other's suggestions & $\bullet$ & & \\
\hline \multicolumn{4}{|l|}{ Negotiation } \\
\hline \multicolumn{4}{|l|}{$\begin{array}{l}\text { Making, watching and responding to each other's } \\
\text { suggestions, opinions, questions (as above) }\end{array}$} \\
\hline Making and demonstrating alternative suggestions & & $\bullet$ & $\bullet$ \\
\hline $\begin{array}{l}\text { Disagreeing - explaining/justifying own ideas, } \\
\text { verbal blocking, physical blocking (shielding, touch-blocking, } \\
\text { knocking others' hands away), } \\
\text { undoing. }\end{array}$ & & $\bullet$ & $\bullet$ \\
\hline \multicolumn{4}{|l|}{ Mechanisms for Coordinating Collaborative Discussion and Action } \\
\hline \multicolumn{4}{|l|}{ Maintaining joint awareness and attention } \\
\hline Narrations & $\bullet$ & $\bullet$ & $\bullet$ \\
\hline \multicolumn{4}{|l|}{ Intrusions * } \\
\hline $\begin{array}{l}\text { Regulation of access ** - ensuring own/others visual (and } \\
\text { physical) access to the screen. }\end{array}$ & $\bullet$ & $\bullet$ & $\bullet$ \\
\hline \multicolumn{4}{|l|}{ Turn-taking** } \\
\hline Taking turns to physically interact; verbally discussing turns & $\bullet$ & $\bullet$ & $\bullet$ \\
\hline
\end{tabular}

Table 2 Summary of children's behaviors across the three case studies

\section{Discussion}

Tablets have become a pervasive learning tool within everyday classrooms. Yet, little is known regarding how these devices are used by children who are paired to work together. Our research examined the types of interactions that occurred around the tablets in order to understand if, when and how collaboration happens. Previous research has often taken a narrow view on collaboration, for example by looking only at learning outcomes or examining the collaborative potential of specific learning tasks and technological set ups, looking for evidence of particular collaborative behaviours such as types of talk, or scoping the analysis to the examination of recognisable instances of effective collaboration. In contrast, we view collaboration as a socially constructed process - where technology shapes collaboration as much as learners' motivations and their relational dynamics - and where collaboration is not fixed but temporal (Mercer, 1994). This view was reflected in our methodological choice to employ a case study approach and video analysis of the interactions of three pairs of children sharing a tablet game. We conducted micro-level coding of each video combined 
with the use of the CLM framework to identify the presence of collaboration mechanisms previously described as indicating children's effective collaborative tabletop interactions. Table 1 shows that many of these collaborative mechanisms also manifest when children use a game designed for single use on a tablet - though these do not always indicate or lead to effective collaboration. Table 1 also demonstrates that tablet surfaces change how collaboration is coordinated (mechanisms for coordinating collaborative discussion and action), more so than how collaborative discussion is held (mechanisms of collaborative discussion and action), reflecting the impact of the tablet resource on coordination.

Revisiting the claim that collaborative learning is shaped by the design of the hardware, the software and learning task, as well as the learners' ways of engaging with the task and with each other (also Mercer, 1994), our analysis sheds light on these dimensions as they shape children's interactions with single player games on tablets. Our aim was to understand the process of collaboration that unfolds in order to orchestrate it more effectively. In what we term collaborative orientation we report that children's (learners') attitude toward each other determines how symmetrical their actions and contributions are. We go on to discuss how the tablet (hardware) impacts on coordination and finally we show the role of the game (software/learning task) in mediating the type of collaborative discussion and action occurring between the pairs. We next discuss these themes drawing implications for theory, collaborative practice and technology design.

\section{Collaborative Orientation}

Each pair of children interacted with a single player game using one tablet. In contrast to multi-touch tabletops, which can be designed to facilitate either joint or parallel activity (Tissenbaum et al., 2017), the games examined in this study did not foster an explicit shared goal in the task, nor did the single player game set up make it possible for both children to play at the same time. It was functionally possible for a child to complete the games by themselves, and collaboration was not necessary to accomplish the task. As a result, children's collaborative orientation, i.e. their positive attitude toward working with each other and their motivation to see each other succeed, became a pre-requisite condition to fluid and effective collaboration on the tablet. Collaboration was consistently practiced only in one of the three pairs (case 1). In line with a social interdependence lens where 'the actions of individuals promote the achievement of joint goals' (Johnson and Johnson, 2009) this pair of children approached the game tasks as a shared activity and collaboration in itself became the shared goal. Whereas recent research has questioned whether a shared task goal is always necessary in collaboration (Tissenbaum et al., 2017), our study shows that alongside a concern over task goals, the goal to collaborate is equally important and thus the collaborative orientation children bring to the task is particularly critical when the learning task itself is not designed to engender joint activity, or to allow children's parallel participation.

One way to encourage a collaborative orientation is to pair up children who are more likely to work constructively with other. However, Dillenbourg (1999) explains the complexities in ascertaining how to set up the initial conditions of collaboration in terms of prior friendships, gender, group composition and so on. This was also evidenced in our case study 1 and 3, where despite the prior friendship of the children, the collaboration dynamics between them were very different. To counteract this, Mercer et al. (2004) found that coaching children to engage in effective conversation with each other when conducting collaborative tasks increased their amount of exploratory talk during learning tasks, suggesting that when children are taught strategies for more effective talk they also take a better collaborative orientation to such tasks. Despite this promising approach, in a yearlong ethnographic study in Danish schools, Davidsen (2016) showed that teachers who subscribed to the collaborative use of tablets in their classroom were themselves not clear how to support children's collaboration in practice. Adding to Davidsen (2016) who suggest that teaching practice must focus on facilitating children's perspective taking, shared meaning and goals, we also posit that children's collaborative orientation can be fostered through scaffolds that encourage the intertwined verbal and physical interactions on the tablet we observed during productive collaboration episodes. Similarly, this recommendation could be applied to multitouch tabletop tasks where collaboration can also be disrupted when children lack a collaborative orientation (see Ioannou et al., 2013).

Identifying the different forms of dependence, Johnson and Johnson (2009) briefly introduce social dependence, i.e., where one person's goal achievements depend on another's actions. Our research shows how social dependence can have a negative impact on collaboration. Within case 3, Penny's desire to see Nina succeed was directed by her own goals to preserve her game score. Though Penny initially supported Nina's game play with collaborative conversation, when Nina's game performance was not perceived to be optimal, Penny became quickly competitive and dominant over Nina. Thus, our study highlights that single player tablet games that additionally bring attention to personal scores and other performance measures can contribute to, and intensify, an individualistic orientation. With the rise of personalised education technologies, further research is needed to explore the ways in which the design of learning technology impacts on children's learning identities and their collaborative orientation toward each other.

\section{Coordinating Collaboration}

All of the pairs, at times, placed the tablet in shared view of each other. This spatial arrangement allowed both children to gauge what was happening in the game play. However, it was only the children from case 1 who coordinated collaboration and engaged in collaborative conversation throughout game play. What is notable is that these mechanisms were closely coupled, i.e., children engaged in task talk and coordinated action at the same time. Focusing on the material resource, i.e., the tablet, joint attention was maintained through both visual and, subsequently, physical access to the tablet. Drawing from our findings, we suggest that the placement of the tablet in relation to the children is essential to enable joint attention. Moreover, a physical design of the tablet that limits portability and increases joint visibility can 
potentially play a role in disrupting children's private use of the tablet. Despite this design implication, however, it is important to recognise that access to the tablet was a necessary but not sufficient condition for collaboration. This was evidenced in case 2 where even though both children had view of the screen, their joint attention was particularly weak. We believe this was shaped as much by the children's lack of collaborative orientation, as by the sequenced form of turntaking they agreed to take.

As we argued earlier, the use of the CLM framework enabled us to recognise that collaborative mechanisms observed around multi-touch tabletops also manifest around tablets. However, as Table 1 indicates, coordination around tablets, in particular, also differed in several ways. For example, turn-taking was not included in the CLM tabletop framework suggesting it was not an important way in which children coordinated their collaboration around tabletops. This might have been because the CLM tabletop framework was based on interactions in an open-ended task around a multi-touch tabletop, and previous work has already suggested that there is less explicit turn-taking talk in a multi-touch tabletop task compared to a single-touch version of the same task (Harris et al., 2009). Therefore, we may have observed more turntaking talk due to the single-touch nature of the game. In addition to children's discussion of turn-taking, however, we also observed the act of physically taking turns whilst around the tablets as a mechanism for coordinating collaboration. Again, the larger format and multi-touch nature of the tabletops, on which the CLM tabletop framework was based, enabled simultaneous interaction in a way that the smaller tablet did not - hence perhaps leading to a more explicit 'turntaking' around the tablet. Our findings corroborate Falloon (2015) who found that despite the possibility for multi-touch interactions on tablets, children are more likely to negotiate turn-taking. Whereas in case 1 turn-taking did not limit collaborative discussion similar to what Jensen et al. (2016) reported, the other two pairs of children, who also coordinated through turn-taking, did not often engage in discussion with one another during the game play. Therefore, while turntaking was important in coordinating collaboration, this was only facilitative of collaborative learning if both children recognised they had a continuing role in the task even when the other child was physically interacting with the tablet.

Regulation of access to the tablet played an important role in coordinating collaboration and maintaining joint attention. This included children ensuring they had visual, and physical, access to the tablet, and on occasion they deliberately placed or oriented the tablet towards their partner to ensure they also had access, and to invite collaborative input. The children sometimes did this to indicate a change in turn. Given the portability of the tablet it was possible for children to completely move it away from their peer, excluding him/her from participating. This is similar to the mechanism 'physical blocking' described around multi-touch tabletop surfaces, where children have been found to protect a limited area or part of the surface, or control access to it. Seemingly 'negative' behaviours, such as blocking or intruding, have been found around multi-touch tabletops and tangibles, to protect children's own ideas or suggestions as part of a process of negotiation, and to bring children more closely together on the task (Falcao and Price, 2009; Fleck et al., 2009). However, around the tablets, the children used blocking access to the tablet as a means of dominating in the task, with little evidence that this led to effective negotiation. This could be attributed to a number of reasons in the cases we observed in our study, including that it was easier to completely block access to the tablet, that the task could be successfully completed individually without requiring any help, and to children's lack of a collaborative orientation to the task. Therefore, such blocking could be seen as an example of preventing the other person from having visual (and physical) access to the tablet (i.e. the opposite of regulation of access). However, as this was not associated with maintaining joint attention it was not included in our CLM tablets version of the framework (which describes the mechanisms of effective collaboration only).

As Table 2 illustrates, across the case studies we also did not observe any examples of the intrusions as described around tabletops in Fleck et al. (2009), where children accidentally physically interrupted one another (usually by reaching across the table) as they were carrying out the task, drawing their attention together. We hypothesise this is because it was less possible for children to be working independently during the game play, and the small form factor of the tablet made it unlikely that a child be unaware of something the other child was doing on the tablet, unless they were focused away from the tablet.

\section{Importance of the Game Mechanic in Collaborative Conversation}

Several empirical studies suggest that the learning task may have a potential impact on collaborative conversation. Falloon and Khoo (2014) compare findings from two separate studies they conducted to posit that open-ended learning tasks may facilitate more critical and thoughtful collaborative conversation between children as compared to closed learning tasks. Contrasting young children's collaborative use of closed apps (e.g. quizzes) with open-ended apps (e.g. telling a story), Kucirkova et al. (2014) found that children tended to present higher exploratory talk during the openended tasks, arguing that this is perhaps due to the multiple solutions these tasks encourage. Our study contributes a new understanding of the collaborative potential of closed tasks through micro level reflections coming from cases 1 and 3 .

In case 1 , children first played the 'Junk Yard', a timed game with a dual learning and game goal. Under the pressure of time the children split the task in a way that led to Daniel narrating the intellectual contributions, and Arthur executing Daniel's choices, or making contributions in achieving the goals of the game mechanics (i.e., stacking the junk). This division of labour was also documented by Jensen et al. (2016) in a multiple tablet collaborative task where one child verbally suggested the action with the other executing it. Division of labour has been previously observed when a more able partner is working with a less able one and a division of labour is set-up where the less able participant is given the more mechanical task. Radziszewska and Rogoff (1991) describe how this leads to missed opportunities for the more able participant to scaffold or extend the learning of the less able participant, and suggests facilitating 'guided participation' as 
a way to encourage this. However, when the same pair of children played the 'Field' game (which had no timed element, or a dual mechanic) it became apparent that both were capable of making symmetric and equal suggestions, as well as engaging in critical negotiation. In contrast to children's game play of 'Junk Yard' in case 1, where contributions were asymmetrical yet focused on the learning content, case 3 highlighted the impact of the game over the learning. When Nina and Penny played the 'Mail Delivery' game (with mechanics akin to the 'Junk Yard') Penny's collaborative conversation only focused on supporting Nina to gain game rewards (i.e., bananas) rather than support her with the learning aim of the game to correctly syllabify words.

Though open-ended tasks might give children the opportunity to engage in more effective collaborative conversation (Falloon and Khoo, 2014) as exemplified through Daniel's and Arthur's interactions we find evidence that closed tasks can also foster effective collaborative conversation. The conclusion was also reached by Wegerif (1996), who found children were very able to engage in effective collaborative talk during directive tasks, after receiving training in how best to discuss with each other. Grounded in our observations from Nina's and Penny's interactions we propose that the collaborative potential of closed tasks may depend on how well they focus the child's attention on the learning content, rather than the game elements of the task, and the time they provide to children to engage in meaningful talk. However, more research is needed to understand the impact of closed task dimensions on collaborative discussion. For example, one type of 'making and accepting suggestions' behaviour, from the CLM tabletops framework, that we observed very little evidence of around the tablets in our cases, was asking for clarification of other's suggestions (see Table 2). Whilst we cannot say conclusively why this was, one possible reason is that the game did not require complex ideas or plans to be created or explained by the children, thus limiting misunderstandings or the need for this kind of clarification.

\section{Conclusion}

Motivated by the everyday use of tablets in schools, the goal of this research was to understand if and how the collaborative learning process occurs when pairs of children engage in single player apps on a tablet, such as a literacy game, in order to inform best practice in these situations, and the design of new apps that facilitate collaboration around tablets. In three case studies, we applied bottom up and top down analysis using a framework previously developed to capture effective collaboration on tabletop surfaces, the CLM. Our findings provide new theoretical insights on how a collaborative process around tablets manifests, as well as implications for design and practice. We find that children interacting around tablets engage in similar patterns of collaborative discussion to those observed in multi-touch tabletops. Symmetrical collaborative discussion, however, depends on whether the learning technology maintains focus on the learning objective and also leaves space for the learners to engage in talk. Alongside showing how closed tasks may inhibit or facilitate effective collaborative discussion, our study provides criteria for designing digital tasks that foster collaborative discussion as well as choosing digital apps (such as games) that support effective collaboration in classroom tablet use. Compared to multi-touch tabletops, we show that tablets change how children coordinate their collaboration. Turn-taking, in particular, which is often used in schools to regulate children's access to resources, can in some cases hinder collaborative discussion. Our study shows the importance of approaching turn-taking as part of a co-constructed space where both children have roles to contribute to the task, through verbal and/or physical actions. In providing children with digital apps that lack a shared goal, it is ever more important to foster their collaborative orientation. Finally, using the CLM framework allowed us to compare collaborative learning around the tablet to an established body of research with tabletops, and it also allowed us to contextualise the framework to tablet-based interactions contributing a methodological tool for future research in this area. Recognising the specific age and learning profile of our participants, we hope future research will corroborate our findings with other child populations.

\section{Acknowledgement}

This work was funded by the ILearnRW (project no: 318803) FP7 ICT EU project and iRead (project no: 731724) H2020 Innovation Action EU Project. We gratefully acknowledge the children who participated in the study. Additionally, we thank Dr Natalia Kucirkova for her comments on an earlier draft of this paper.

\section{REFERENCES}

Benton, L., Vasalou, A., Berkling, K., Barendregt, W. and Mavrikis, M. In Proceedings of the 2018 CHI Conference on Human Factors in Computing Systems (CHI '18). ACM, New York, NY, USA, Paper 373, 12 pages.

Brudy, F., Suwanwatcharachat, S., Zhang, W., Houben, S., \& Marquardt, N. (2018). EagleView: A Video Analysis Tool for Visualising and Querying Spatial Interactions of People and Devices. In Proceedings of the 2018 ACM International Conference on Interactive Surfaces and Spaces (pp. 6172).

Clark, W., \& Luckin, R. (2013). iPads in the Classroom. What The Research Says.

Davidsen, J. a. V., R. 'You should collaborate, children': a study of teachers' design and facilitation of children's collaboration around touchscreens. Technology, Pedagogy and Education, 25, 5 (2016), 573-593.

Derry, S. J., Pea, R.D., Barron, B., Engle, R.A, Erickson, F., Goldman, R., Hall, R., Koschmann, T., Lemke, J.L., Sherin, M.G., and Sherin, B.L. Conducting Video Research in the Learning Sciences: Guidance on Selection, Analysis, Technology, and Ethics. Journal of the Learning Sciences, 19 (2010), 3-53.

Dillenbourg, P. What do you mean by collaborative learning? Elsevier, 1999.

Do-Lenh, S., Kaplan, F., \& Dillenbourg, P. (2009, September). based concept map: The effects of tabletop on an expressive collaborative learning task. In Proceedings of the 23rd British HCI Group Annual Conference on People and Computers: Celebrating People and Technology (pp. 149-158). British Computer Society. 
Falcão, T. and Price., S. What have you done! The role of 'interference' in tangible environments for supporting collaborative learning. International Society of the Learning Sciences, City, 2009.

Falloon, G. and Khoo., E. Exploring young students' talk in iPad-supported collaborative learning environments. Computers \& Education, 77 (2014), 1328

Falloon, G. What's the difference? Learning collaboratively using iPads in conventional classrooms. Computers \& Education, 87 (2015), 62-77.

Fleck, R., Rogers, Y., Yuill, N., Marshall, P., Carr, A., Rick, J. and Bonnett, V. 2009. Actions speak loudly with words: unpacking collaboration around the table. In Proceedings of the ACM International Conference on Interactive Tabletops and Surfaces (ITS '09). ACM, New York, NY, USA, 189196. DOI: https://doi.org/10.1145/1731903.1731939

Flyvbjerg, B. Five Misunderstandings About Case-Study Research. Qualitative Inquiry, 12, 2 (2006), 219-245.

Halloluwa, T., Vyas, D., Usoof, H., and Hewagamage, K. P. 2018. Gamification for development: a case of collaborative learning in Sri Lankan primary schools. Personal Ubiquitous Comput. 22, 2 (April 2018), 391-407. DOI: https://doi.org/10.1007/s00779-017-1073-6

Harris, A., Rick, J., Bonnett, V., Yuill, N., Fleck, R., Marshall, P., and Rogers, Y. Around the table: are multiple-touch surfaces better than single-touch for children's collaborative interactions?. In Proceedings of the International conference on Computer supported collaborative learning (CSCL'09) (2009). International Society of the Learning Sciences.

Haßler, B., Major, L. and Hennessy, S. Tablet use in schools: a critical review of the evidence for learning outcomes. Journal of Computer-Assisted Learning, 32 (2015), 139-156.

Hornecker, E., Marshall, P., Dalton, N. and Rogers, Y. Collaboration and Interference: Awareness with Mice or Touch Input. In Proceedings of the Conference on Computer supported cooperative work (San Diego, 2008). ACM Press, San Diego.

Ioannou, A., Christofi, M., \& Vasiliou, C. (2013). A Case study of interactive tabletops in education: Attitudes, issues of orientation and asymmetric collaboration. In European Conference on Technology Enhanced Learning (pp. 466-471). Springer, Berlin, Heidelberg.

Jensen H.I., Olsen, M., and Skov, M.B.. 2016. PinchPan: Investigating Children's Collaboration in Cross-Device Interaction. In Proceedings of the 13th International Conference on Advances in Computer Entertainment Technology (ACE '16). Association for Computing Machinery, New York, NY, USA, Article 9, 1-6.

Johnson, D.W. and Johnson, R.T. An Educational Psychology Success Story: Social Interdependence Theory and Cooperative Learning. Education Researcher 38, 5 (2009).

Kucirkova, N. M., D., Sheehy, K., Fernández Panadero, C. Children's engagement with educational iPad apps: Insights from a Spanish classroom. Computers \& Education, 71 (2014), 175-184.

Lai, E. R. Collaboration: A Literature Review. Pearson Assessments. http://images.pearsonassessments.com/images/tmrs/Collaboration-Review.pdf. 2011. Mercer, N. and Wegerif, R. Is 'exploratory talk' productive talk? Routledge, City, 1998.

Mercer, N. The quality of talk in children's joint activity at the computer. Journal of Computer-Assisted Learning, 10, 1 (1994), 24-32

Mercer, N., Littleton, K., Wegerif, R. Methods for studying the processes of interaction and collaborative activity in computer-based educational activities. Technology, Pedagogy and Education, 13, 2 (2004), 193-209.

Piper, A. M., \& Hollan, J. D. (2009, April). Tabletop displays for small group study: affordances of paper and digital materials. In Proceedings of the SIGCHI Conference on Human Factors in Computing Systems (pp. 1227-1236). ACM.

Radziszewska, B., \& Rogoff, B. (1991). Children's guided participation in planning imaginary errands with skilled adult or peer partners. Developmental Psychology, 27(3), 381.

Rick, J., Harris, A., Marshall, P., Fleck, R., Yuill, N. and Rogers, Y. Children Designing Together on a Multi-Touch Tabletop: An Analysis of Spatial Orientation and User Interactions. In Proceedings of the Interaction Design and Children (2009). ACM Press, Como, Italy.

Stebbins, R.A. Exploratory research in the social sciences. Sage. 2001.

Tissenbaum, M., Berland, M. Lyons, L. (2017). DCLM framework: understanding collaboration in open-ended tabletop learning environments

Underwood, G., \& Underwood, J. (2002). Task effects on co-operative and collaborative learning with computers. In Learning with computers (pp. 24-37). Routledge.

Wegerif, R. (1996) Collaborative learning and directive software, fournal of Computer Assisted Learning, 12, 1, 22-32, March - ISSN 0266-4909

Yin, R. Case Study Research: Design and Methods. SAGE Publications, 2018.

Dimitriadis, Y., Prieto, L. P., \& Asensio-Pérez, J. I. (2013). The role of design and enactment patterns in orchestration: Helping to integrate technology in blended classroom ecosystems. Computers \& Education, 69, 496-499. 